\title{
Photodynamic therapy reduces the inhibitory effect of osteosarcoma cells on dendritic cells by upregulating HSP70
}

\author{
FAN ZHANG ${ }^{*}$, YANJIE ZHU*, GUOXIN FAN ${ }^{*}$ and SHUO HU \\ Department of Orthopedics, Shanghai Tenth People's Hospital, \\ Tongji University School of Medicine, Shanghai 200072, P.R. China
}

Received June 20, 2017; Accepted February 27, 2018

DOI: $10.3892 / 01.2018 .9322$

\begin{abstract}
Osteosarcoma is the most common primary bone tumor and predominantly affects children and adolescents. The prognosis for patients with osteosarcoma is poor. Therefore, the development of novel treatments for osteosarcoma is required. Photodynamic therapy (PDT) is a disease site-specific treatment that utilizes a photosensitizing agent along with light to kill cancer cells. This agent only works following activation by certain wavelengths of light. After the agent is absorbed by the cancer cells, light is then applied to the area to be treated. The light causes the drug to react with oxygen, which produces radical and reactive oxygen species that kill the cells. However, the immune reaction that occurs following PDT remains unknown. The present study demonstrated that the necrosis of osteosarcoma cells inhibited the function of dendritic cells. However, treatment of osteosarcoma cells with PDT restored the function of dendritic cells by upregulating heat shock protein 70 . Taken together, the results of the present study provided insight into the subsequent molecular reaction following PDT treatment of osteosarcoma at the molecular level.
\end{abstract}

\section{Introduction}

Osteosarcoma is the most common primary bone tumor and predominantly affects children and adolescents (1-3). The current treatment of osteosarcoma remains difficult, and osteosarcoma causes numerous mortalities due to its complex pathogenesis and resistance to conventional treatments (4).

Photodynamic therapy (PDT) is a disease site-specific treatment. It involves the local systemic administration of

Correspondence to: Dr Shuo Hu, Department of Orthopedics, Shanghai Tenth People's Hospital, Tongji University School of Medicine, 301 Yanchang Road, Shanghai 200072, P.R. China

E-mail: hushuo10hospital@163.com

*Contributed equally

Key words: osteosarcoma, photodynamic therapy, dendritic cells, HSP70 a photosensitizer followed by irradiation of the targeted lesion site with non-thermal visible light of an appropriate wavelength. In the presence of molecular oxygen, the light irradiation of the photosensitizer and energy transfer may lead to a number of photochemical reactions and generation of various cytotoxic species, thereby inducing apoptosis and necrosis of the targeted lesion (5). Osteosarcoma has been studied by our group for a number of years and have investigated the possibility of applying PDT to the treatment of osteosarcoma $(6,7)$.

Previously, another study indicated that PDT causes acute inflammation, expression of heat-shock proteins, invasion and the infiltration of the tumor by leukocytes, and that it may increase the presentation of tumor-derived antigens to $\mathrm{T}$ cells by regulating dendritic cells (DCs) (8).

DCs are a heterogeneous population of antigen-presenting cells. Their main function is to process antigens and present them to $\mathrm{T}$ cells to promote immunity toward foreign antigens and tolerance toward self-antigens (9-15). It has been demonstrated that the inflammation milieu induced by PDT promoted the antigen-presenting function of DCs (16).

It has been previously reported that PDT treatment results in the induction of apoptotic and necrotic cell death, and that immature DCs co-cultured with PDT-treated tumor cells results in effective homing to regional and peripheral lymph nodes and stimulation of the cytotoxic activity of $\mathrm{T}$ and natural killer cells (17). However, the exact mechanism by which the DCs are initiated remains unclear. In the study, we firstly hypothesized that the necrosis of osteosarcoma cells inhibited the function of DCs and treatment with PDT restored the function of DCs. The present study may provide insight into the mechanism underling the function of DCs following the treatment of osteosarcoma via PDT.

\section{Materials and methods}

Mice. A total of $20 \mathrm{C} 57 \mathrm{BL} / 6$ mice (6-8 weeks old, $21 \pm 2.1 \mathrm{~g}$, male) were obtained from the Animal Center of the Second Military Medical University (Shanghai, China). A total of 10 DO11.10 OVA $323-339$-specific mice (6-8 weeks old, 21 $22.1 \mathrm{~g}$, male) with C57BL/6 background were obtained from the Jackson Laboratory (C57BL/6 x DO11.10). A total of $10 \mathrm{~F} 1$ mice $(21 \pm 2.1 \mathrm{~g}$, male) were prepared by crossing C57BL/6 mice with DO11.10 mice. All mice were maintained under specific pathogen-free conditions and used at 6-8 weeks of 
age. Mice were provided with ad libitum access to food and water. Room conditions were controlled for humidity (40-70\%) and temperature $\left(22 \pm 3^{\circ} \mathrm{C}\right)$ with a $12 / 12 \mathrm{~h}$ light/dark cycle. The use of the mice was approved by the Ethics Committee of Tongji University (Shanghai, China).

Photodynamic therapy. The photodynamic treatments were performed at the Department of Orthopedics of Shanghai Tenth People's Hospital (Shanghai, China). The entire process was performed as previously described (18).

Cell culture and treatment. The murine osteosarcoma LM8 cell line was obtained from the Type Culture Collection of Chinese Academy of Sciences (Manassas, VA, USA) and was cultured in Dulbecco's modified Eagle's medium (catalog no. SH30022.01; Hyclone, GE Healthcare Life Sciences, Logan, UT, USA), containing $10 \%$ fetal bovine serum (cat. no. 10100139; FBS; Gibco; Thermo Fisher Scientific, Inc., Waltham, MA, USA), $1 \%$ penicillin and $1 \%$ streptomycin. Cells were placed at $37^{\circ} \mathrm{C}$ in a humidified $5 \% \mathrm{CO}_{2}$ incubator. The remnants of LM8 cells were produced by Ultrasonic Cell Disruptor (Fisherbrand ${ }^{\mathrm{TM}}$ Model 505 Sonic Dismembratorm; Thermo Fisher Scientific, Inc.) at 300 watts for $10 \mathrm{sec}$. Mouse bone marrow-derived DCs were generated by culturing in granulocyte-macrophage colony-stimulating factor (GM-CSF; catalog no. 12-7209-42; Thermo Fisher Scientific, Inc.) and interleukin (IL)-4 (catalog no. 1-7042-82; Thermo Fisher Scientific, Inc.), as previously described (19-22). In brief, the back legs above the hip joint of each mouse were incised, with the knee and ankle joints intact. Following this, both ends of the bone were incised with scissors as close to the joints as possible, then a syringe was filled with ice-cold RPMI complete medium (cat no. 21875091; Gibco; Thermo Fisher Scientific, Inc.) and the syringe needle was inserted into the bone in order to flush out the bone marrow into a centrifuge tube, which was on ice. Following depletion of red cells, the suspensions were cultured at a density of $2 \times 10^{6}$ cells $/ \mathrm{ml}$ in RPMI-1640 medium (Gibco; Thermo Fisher Scientific, Inc.) with $10 \%$ fetal calf serum. rmGM-CSF (10 ng/ml; cat no. PMC2015; Thermo Fisher Scientific, Inc.) and rmIL-4 (1 ng/ml; cat no. RMIL4; Thermo Fisher Scientific, Inc.) were added at the beginning of the cell culture. The non-adherent cells were gently washed at day 3 or day 4 . On day 5 , the proliferating DC clusters were collected and purified by anti-CD11c microbeads (cat no. 130092465; Miltenyi Biotec GmbH, Bergisch Gladbach, Germany) as immature DCs. Immature DCs were stimulated with LPS (1 $\mu \mathrm{g} / \mathrm{ml}$; cat no. 00-4976-93; Thermo Fisher Scientific, Inc.) for $12 \mathrm{~h}$, and these cells were collected as mature DCs. The purity of the DCs was $>95 \%$, confirmed anti-CD11c conjugated to fluorescein isothiocyanate (cata no. 11-0114-85; Thermo Fisher Scientific, Inc.) by cytometry analysis (BD LSR II; BD Biosciences, Franklin Lakes, NJ, USA) as previously described (23). The bone marrow-derived DCs were co-cultured with the remnants of osteosarcoma LM8 cells. DCs co-cultured with RPMI complete medium (cat no. 21875091; Gibco; Thermo Fisher Scientific, Inc.) with $10 \%$ fetal bovine serum (cat. no. 10100139; FBS; Gibco; Thermo Fisher Scientific, Inc., Waltham, MA, USA) were used as the control. The cells were placed at $37^{\circ} \mathrm{C}$ in a humidified $5 \% \mathrm{CO}_{2}$ incubator for $24 \mathrm{~h}$.
Phenotype analysis. For assessing the DC phenotypes, cells were incubated with blocking buffer $(0.5 \%$ BSA and $0.05 \%$ Sodium Azide in $1 \mathrm{x}$ PBS) at room temperature for $30 \mathrm{~min}$. These cells $\left(5 \times 10^{5}\right)$ were subsequently stained independently with fluorescein-conjugated monoclonal antibodies against cluster of differentiation CD80 (catalog no. 11-0809-42; 1:500), CD86 (catalog no. 12-0869-42; 1:1,000), Ia (catalog no. 11-0432-42; 1:1,000) or CD40 (catalog no. 11-1548-42; 1:1,000) (all Thermo Fisher Scientific, Inc.) in staining buffer (1\% FBS with $0.09 \% \mathrm{NaN} 3$ ) at room temperature for $20 \mathrm{~min}$. Following washed by PBS three times and centrifugation at $500 \mathrm{x}$ for $3 \mathrm{~min}$ at $4^{\circ} \mathrm{C}$, cells were subsequently analyzed by FACS (BD LSR II) for expression of CD80, CD86, Ia and CD40. For assessing the myeloid-derived suppressor cell phenotypes, cells $\left(5 \times 10^{5}\right)$ were double-stained with fluorescein-conjugated monoclonal antibodies against Gr-1 and CD11b, and then these cells were analyzed by FACS using a BD LSR II flow cytometer (LSR II, 1.1.0) with BD FACSDiva ${ }^{\mathrm{TM}}$ software version 6.0 (BD LSR II; BD Biosciences, Franklin Lakes, NJ, USA) for Gr-1 and CD11b expression.

T-cell proliferation analysis. Ability of DCs in stimulating $\mathrm{T}$ cell proliferation were tested by DC-T cell cocultured experiment. In detail, $\mathrm{OVA}_{323-339^{-}}$-specific $\mathrm{T}$-cell receptor (TCR)-transgenic mice (6-8 weeks) were euthanized for isolation of the spleen. The single-cell suspensions of spleen were produced by gentle grinding and filtration, and then the red blood cells were removed via red blood cell Lysis Buffer (cat. 00-433-57; Thermo Fisher Scientific, Inc.). The CD4 ${ }^{+} \mathrm{T}$ cells were purified using microbeads $\left(\mathrm{CD}^{+}\right.$antibody-coated; Miltenyi Biotec $\mathrm{GmbH})$. The $\mathrm{CD}^{+} \mathrm{T}$ cells $\left(1 \times 10^{5}\right)$ were co-cultured with DCs $\left(1 \times 10^{4}\right)$ in 96 -well plates for 5 days. The viable T cells $\left(\mathrm{CD}^{+}{ }^{+}\right.$and $\left.7-\mathrm{AAD}^{-}\right)$were then counted by using a BD LSR II flow cytometer (LSR II, 1.1.0) with BD FACSDiva ${ }^{\mathrm{TM}}$ software version 6.0 (BD LSR II; BD Biosciences).

RNA sequencing ( $R N A-S E Q)$ and reverse transcription-quantitative polymerase chain reaction ( $R T-q P C R)$. Total RNA were extracted from LM8 cells by TRIzol ${ }^{\circledR}$ Reagent (catalog no. 15596018, Thermo Fisher Scientific, Inc.). RNA-SEQ was performed by Shanghai Shengong Engineering Technology Service, Ltd. (Shanghai, China). The expression levels of heat shock protein 70 (HSP70), activating transcription factor 3 (ATF3), B-cell lymphoma 2 (Bcl-2), tumor protein (P)53, P21, P16 and P27 levels were analyzed by RT-qPCR. RNA were reversed-transcrpted by SuperScript ${ }^{\mathrm{TM}}$ First-Strand Synthesis System for RT-PCR (catalog no. 11904018, Thermo Fisher Scientific, Inc). The thermocycling conditions were $42^{\circ} \mathrm{C}$ for $50 \mathrm{~min}, 70^{\circ} \mathrm{C}$ for $15 \mathrm{~min}$. PCR primers were constructed by Shanghai Shengong Engineering Technology Service, Ltd. qPCR reactions were performed in 96-well optical reaction plates using the cDNA equivalent of $20 \mathrm{ng}$ total RNA for each sample in a total volume of $20 \mu \mathrm{l}$ containing $1 \mathrm{X} \mathrm{SYBR}^{\circledR}$ Green PCR master mix (24) (cat. no. A25741; Thermo Fisher Scientific) and forward and reverse primers were listed as following: HSP70, forward, 5'-GATGCCAGCGTACAG TCC-3', reverse, 5'-ACAGCATTTGTCACTGTCTTT-3'; ATF3, forward, 5'-TGCAAAAGGAAACTGACCAAG-3', and reverse, 5'-CTGGCCTGGATGTTGAAGCAT-3'; p53, 
A

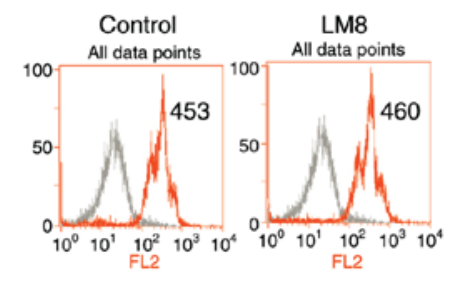

MHC-2
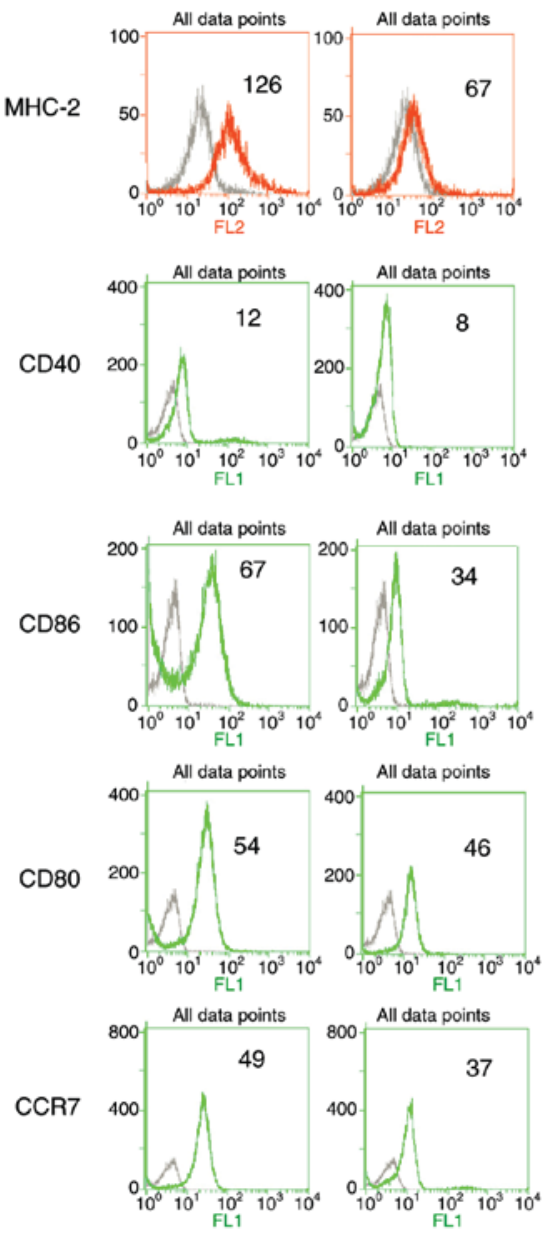

B
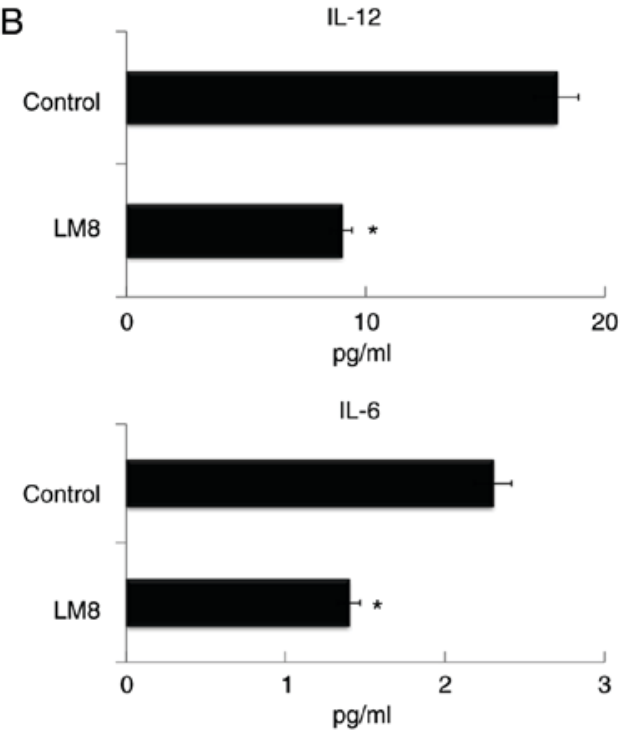

IL-10

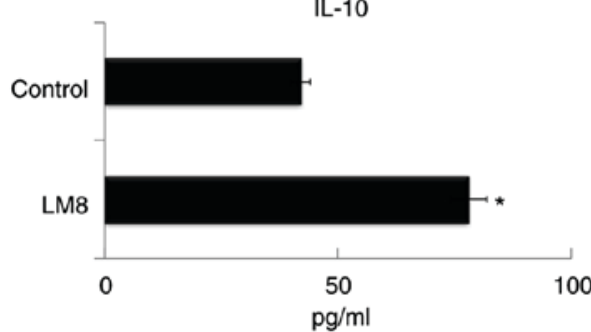

C No $\mathrm{DC} / \mathrm{T}$

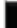

Control
DC/T

LM8 DC/

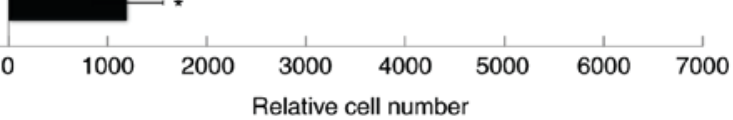

Figure 1. The remnants of LM8 decreased the co-stimulatory molecules, and inhibited IL-12 and IL-6 levels, increased IL-10 levels, and inhibited the ability of DCs to stimulate T-cell proliferation. (A) The DCs were isolated following a 48-h co-culture with the remnants of LM8 cells. The cells were then labeled with antibodies against CD11c, MHC-2, CD40, CD86, CD80 and CCR7 for phenotypic analysis by flow cytometry. The numbers in the histograms indicate the geometric mean fluorescence intensity. (B) Following isolation from the co-culture system, the DCs were cultured for $12 \mathrm{~h}$. Subsequently, the expression levels of IL-12, IL-6 and IL-10 in the supernatant were analyzed by ELISA. (C) CD4 ${ }^{+} \mathrm{T}$ cells from DO11.10 $\mathrm{OVA}_{323-339^{-}}$-specific (TCR-transgenic x C57BL/6) F1 hybrid mice were co-cultured with DCs or mDCs (control) in the presence of OVA peptides. Five days later, the total number of viable $\left.\mathrm{CD}^{+} \mathrm{T}^{(\mathrm{CD} 4}{ }^{+} 7-\mathrm{AAD}^{-}\right)$ cells in each well was measured by flow cytometry. Data represent one of at least three experiments with similar results. "P<0.05 LM8 DC/T vs. Control DC/T. IL, interleukin; DCs, dendritic cells; CD, cluster of differentiation; MHC-2, major histocompatibility complex 2; CCR7, C-C chemokine receptor 7; DC/T, DCs and $\mathrm{T}$ cell co-culture; mDCs, mature DCs.

forward, 5'-CCCCTCCTGGCCCCTGTCATCTTC-3', and reverse, 5'-GCAGCGCCTCACAACCTCCGTCAT-3'; p21, forward, 5'-GAGGCCGGGATGAGTTGGGAGGAG-3', and reverse 5'-CAGCCGGCGTTTGGAGTGGTAGAA-3'; p16, forward, 5'-GAGCAGCATGGAGCCTTCGG, and reverse, 5'-CATGGTTACTGCCTCTGGTG-3'; p27, forward, 5'-GGTTAGCGGAGCAATGCG-3', and reverse, 5'-TCC ACAGAACCGGCATTTG-3'; GAPDH, forward, 5'-CGA CCACTTTGTCAAGCTCA-3', and reverse, 5'-AGGGGT CTACATGGCAACTG-3'. The thermocycling conditions were as follows: $95^{\circ} \mathrm{C}$ for $3 \mathrm{~min}$ and 40 cycles of amplification comprising $95^{\circ} \mathrm{C}$ for $12 \mathrm{sec}$, appropriate annealing temperature $\left(60^{\circ} \mathrm{C}\right)$ for $30 \mathrm{sec}$, and $72^{\circ} \mathrm{C}$ for $30 \mathrm{sec}(25-27)$.
Statistical analysis. A two-tailed unpaired Student's t-test was used to analyze the difference between two groups. Analysis of variance, followed by the least significant difference test, was used to analyze the difference among three groups. SPSS for Windows, v.16.0 (SPSS Inc., Chicago, IL, USA), was used to perform all statistical analyses. Values are expressed as the mean \pm standard deviation of three independent tests. $\mathrm{P}<0.05$ was considered to indicate a statistically significant difference.

\section{Results}

The remnants of LM8 cells inhibit the function of DCs. To begin with, the effects of the lysis remnants of osteosarcoma 
A $\mathrm{MHC}-2$
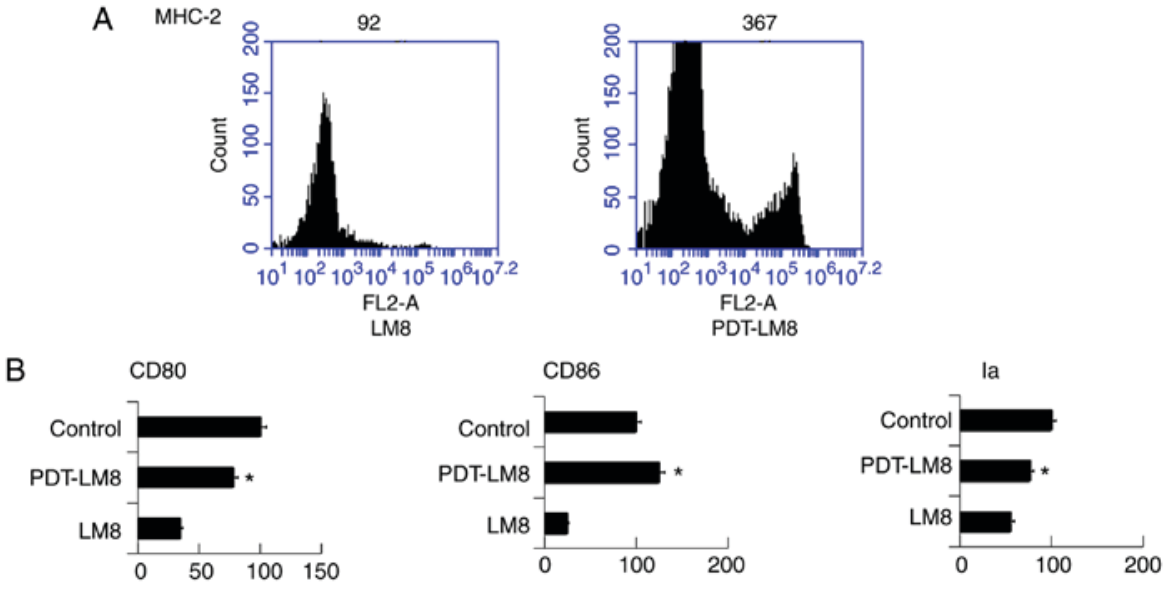

Geometric mean fluorescence intensity
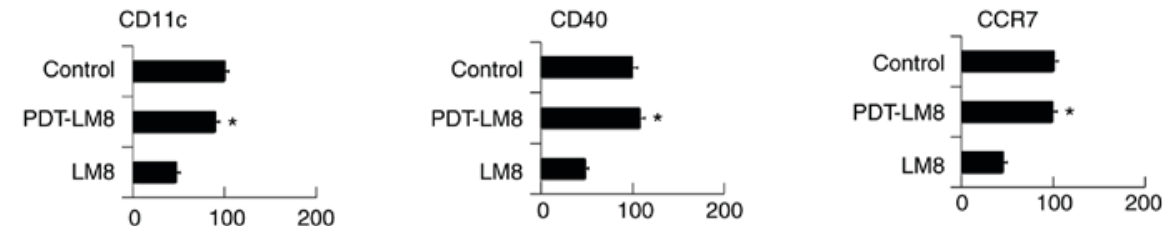

Geometric mean fluorescence intensity

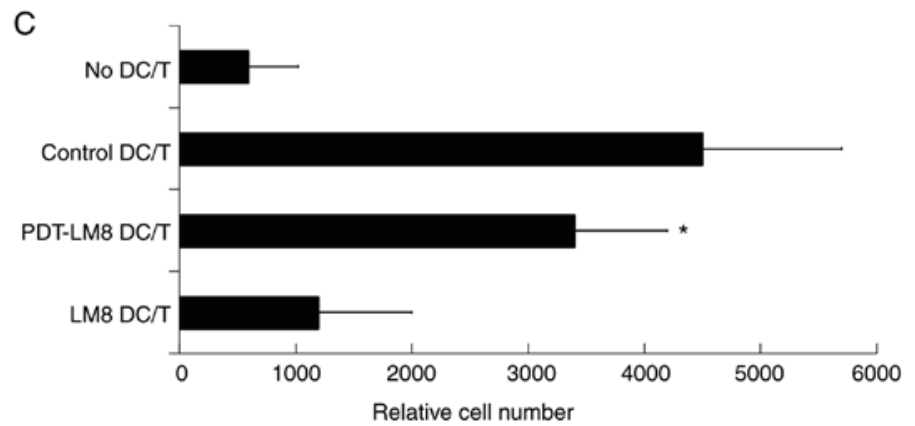

Figure 2. PDT treatment partly reversed the effect of LM8 remnants on the phenotype of DCs and their ability to stimulate T cells proliferation. (A) The LM8 cells were pre-treated with PDT, and then labeled with antibodies against MHC-2, CD11c, CD40, CD86, CD80 and CCR7, for phenotypic analysis by flow cytometry. (B) The numbers in the histograms indicate the geometric mean fluorescence intensity. ${ }^{~} \mathrm{P}<0.05$ PDT-LM8 vs LM8. (C) CD4 ${ }^{+}$T cells from DO11.10 $\mathrm{OVA}_{323-339^{-}}$-specific (TCR-transgenic x C57BL/6) F1 hybrid mice were co-cultured with DCs or mDCs (control) in the presence of OVA peptides. Five days later, the total number of viable $\mathrm{CD}^{+} \mathrm{T}\left(\mathrm{CD}^{+}\right.$7- $\left.\mathrm{AAD}^{-}\right)$cells in each well was measured by flow cytometry. Data represent one of at least three experiments with similar results. "P<0.05 PDT-LM8 DC/T vs LM8 DC/T. PDT, photodynamic therapy; DCs, dendritic cells; MHC-2, major histocompatibility complex 2; $\mathrm{CD}$, cluster of differentiation; CCR7, C-C chemokine receptor 7; DC/T, DCs and T cell co-culture.

cells on the function of DCs were determined. The bone marrow-derived DCs were co-cultured with the remnants of osteosarcoma LM8 cells. DCs co-cultured with medium were used as control. After a 48-h co-culture, the DCs were isolated for phenotype and cytokine analysis, and their ability to stimulate the proliferation of T-cells was also investigated. It was revealed that the remnants of LM8 cells significantly inhibited the expression of major histocompatibility complex 2 (MHC-2), CD40, CD86, CD80 and C-C chemokine receptor type 7 (Fig. 1A). The treatment of LM8 cells decreased IL-12 levels and increased IL-10 levels (Fig. 1B). The mixed lymphocyte reaction analysis revealed that the treatment of LM8 cells decreased the ability of DCs to stimulate T-cell proliferation (Fig. 1C).

PDT treatment reduces the inhibitory function of the LM8 remnants. To investigate the role of PDT in the inflammation, we first treated LM8 cells with PDT and then collected the remnants of LM8 treated cells (PDT-LM8) for co-cultured with the bone marrow-derived DCs. We found that PDT-LM8 upregulated MHC-2 expression (Fig. 2A). We then analyzed the co-expression molecules and found that PDT-LM8 treated by PDT up-regulated the CD80, CD86, Ia, CD11c, CD40, and CCR7 (Fig. 2B). The mixed lymphocyte reaction analysis revealed that the PDT treatment may increase the ability of DCs in stimulating $\mathrm{T}$ cell proliferation (Fig. 2C).

HSP70 is upregulated by PDT. To identify the key molecular elements altered in osteosarcoma cells treated with PDT, the differential gene expression between LM8 cells treated with PDT and the control was determined by RNA-SEQ analysis. The data indicated that HSP70 was upregulated in the PDT-treated LM8 cells (Fig. 3A). As HSP70 serves an important role in the activation of DCs (28-30), the expression of HSP70 and related genes, including ATF3, BCL2, P53, P21, P16 and P27, was subsequently assessed by RT-qPCR. It was revealed that HSP70 was upregulated following PDT treatment (Fig. 3B). Next, the HSP70 levels were inhibited in 

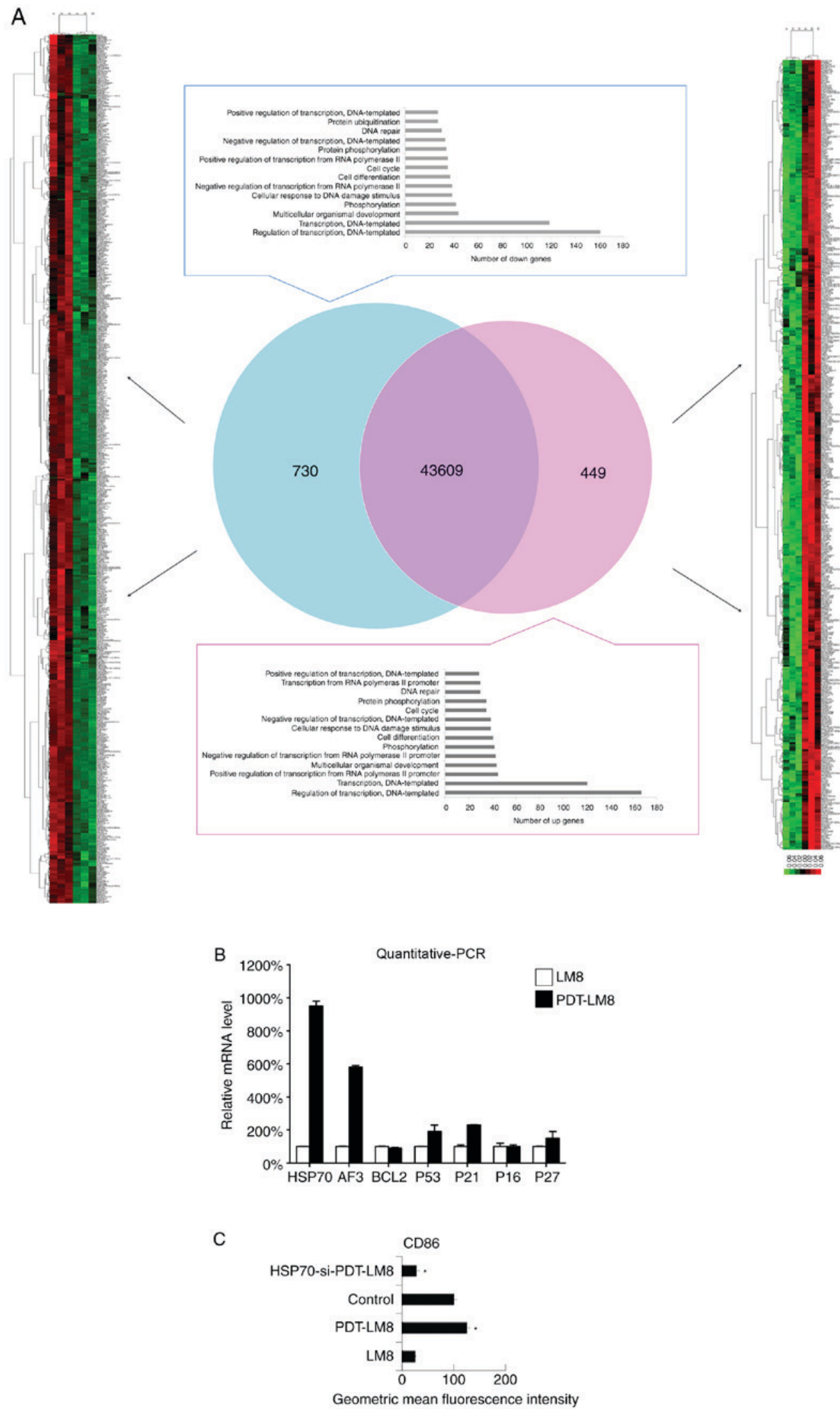

Figure 3. PDT treatment upregulated the HSP70 expression in LM8 cells and promoted upregulation of HSP70-activated DCs. (A) The LM8 cells with and without PDT pre-treatment were collected for RNA sequencing analysis. (B) The expression of HSP70, ATF3, Bcl-2, P53, P21, P16 and P27 was analyzed by reverse transcription-quantitative PCR. (C) LM8 cells were transfected with HSP70 small interfering RNA, and the DCs were then co-cultured with LM8 for $48 \mathrm{~h}$, prior to being labeled with an antibody against CD86 for phenotypic analysis by flow cytometry. The numbers in the histograms indicate the geometric mean fluorescence intensity. Data represent one of at least three experiments with similar results. "P<0.05 HSP70-si-PDT-LM8 vs PDT-LM8. PDT, photodynamic therapy; HSP70, heat shock protein 70; DCs, dendritic cells; ATF3, activating transcription factor 3; Bcl-2, B-cell lymphoma 2; PCR, polymerase chain reaction; CD, cluster of differentiation. 
LM8 cells via siRNA and then the remnants of these transfected LM8 cells were cultured with DCs. It was observed that the increased downregulation of HSP70 cells at least partly reduced the effect of PDT treatment on the phenotype of DCs (CD86 expression). Therefore, it was concluded that the HSP70 expression induced by PDT may promote the function of DCs (Fig. 3C).

\section{Discussion}

PDT is a novel approach for the treatment of osteosarcoma. However, the underlying mechanisms affecting subsequent immune reaction remains unclear. The present study provided insights into these molecular mechanisms and revealed that the remnants of osteosarcoma cells inhibited the functions of DCs and that treatment with PDT reduced this inhibitory function. Notably, the upregulation of HSP70 was involved in the underlying mechanism regarding this phenomenon.

It has been established that the function of DCs in tumors is inhibited. In a previous study, authors revealed that the tumor microenvironment was able to induce DCs to differentiate into regulatory DCs with a CD11c(low) CD11b(high) $\mathrm{Ia}($ low) phenotype and a high expression of IL-10, nitric oxide, vascular endothelial growth factor and arginase I. These tumor-educated regulatory DCs suppress T cell response (31). Notably, PDT treatment changed the gene expression of osteosarcoma cells and induced upregulation of HSP70. HSP70 has been demonstrated to activate the function of DCs (28-30). As it has been established that tumor-educated DCs develop into DCs with immune suppressive functions. The present study revealed that PDT treatment promoted the normal function of DCs.

However, for CD11c(low) CD11b(high) Ia(low) regulatory DCs, tumor-derived transforming growth factor $\beta$ (TGF- $\beta$ ) and prostaglandin E2 (PGE2) are responsible for the generation of regulatory DCs. The present study revealed that upregulation of HSP70 reversed the inhibitory function of the tumor on DCs. Therefore, we concluded that there were two possible reasons for this: i) PDT treatment may prevent the process of tumor-educated DCs via HSP70, or ii) PDT treatment may re-educate the tumor-educated DCs in a HSP70-dependent manner.

In the process of inducing DCs with immune suppressive functions, the soluble factors TGF- $\beta$ and PGE2 served central roles. Following PDT treatment, HSP70, an insoluble factor, was able to reverse the function of DCs. Therefore, the results of the present study indicated that soluble factors and other molecules expressed by tumors may affect the function of DCs.

Furthermore, these data also indicated that that p53 was upregulated following treatment of LM8 cells with PDT (Fig. 2B). However, it was previously demonstrated that the p53 gene was most often mutated/deleted in human osteosarcoma $(32,33)$, and it is possible that the OS cell lines used in those studies lacked p53 expression. Due to the fact that the results of the present study cannot confirm that p53 was upregulated by PDT treatment, this will be investigated in future studies.

In conclusion, the results of the present study revealed that the remnants of osteosarcoma treated with PDT induced the activation of DCs, and that the molecular mechanism involved upregulation of HSP70 expression induced by PDT. Therefore, the present study may provide novel insight into the treatment of osteosarcoma via PDT and its effects on the function of DCs.

\section{Acknowledgements}

The authors would like to thank Dr Chaoxiong Zhang (Research Center for Public Health and Preventive Medicine, West China School of Public Health, Sichuan Univeristy, Chengdu, China) for their assistance.

\section{Funding}

No funding was received.

\section{Availability of data and materials}

All data generated or analyzed during this study are included in this published article.

\section{Authors' contributions}

FZ and YZ collected patient data and performed cell experiments. GF performed the PCR molecular experiment and FACS. SH contributed to the study design and manuscript writing.

\section{Ethics statement and consent to participate}

The present study was approved by Ethics Committee of Tongji University (Shanghai, China).

\section{Patient consent for publication}

Not applicable.

\section{Competing interests}

The authors declare that they have no competing interests.

\section{Reference}

1. Mirabello L, Troisi RJ and Savage SA: Osteosarcoma incidence and survival rates from 1973 to 2004: Data from the surveillance, epidemiology, and end results program. Cancer 115: 1531-1543, 2009.

2. Kansara M and Thomas DM: Molecular pathogenesis of osteosarcoma. DNA Cell Biol 26: 1-18, 2007.

3. Ottaviani G and Jaffe N: The epidemiology of osteosarcoma. Cancer Treat Res 152: 3-13, 2009.

4. Miao J, Wu S, Peng Z, Tania M and Zhang C: MicroRNAs in osteosarcoma: Diagnostic and therapeutic aspects. Tumor Biol 34: 2093-2098, 2013.

5. Huang Z: A review of progress in clinical photodynamic therapy. Technol Cancer Res Treat 4: 283-293, 2005.

6. Gong HY, Sun MX, Hu S, Tao YY, Gao B, Li GD, Cai ZD and Yao JZ: Benzochloroporphyrin derivative induced cytotoxicity and inhibition of tumor recurrence during photodynamic therapy for osteosarcoma. Asian Pac J Cancer Prev 14: 3351-3355, 2013.

7. Zeng H, Sun M, Zhou C, Yin F, Wang Z, Hua Y and Cai Z: Hematoporphyrin monomethyl ether-mediated photodynamic therapy selectively kills sarcomas by inducing apoptosis. PloS One 8: e77727, 2013. 
8. Castano AP, Mroz P and Hamblin MR: Photodynamic therapy and anti-tumour immunity. Nat Rev Cancer 6: 535-545, 2006.

9. Merad M: Dendritic cells: Controllers of adaptive immunity. Nat Rev Immunol 11: 1-2, 2011.

10. Schuler G, Schuler-Thurner B and Steinman RM: The use of dendritic cells in cancer immunotherapy. Curr Opin Immunol 15: $138-147,2003$

11. Merad M, Sathe P, Helft J, Miller J and Mortha A: The dendritic cell lineage: Ontogeny and function of dendritic cells and their subsets in the steady state and the inflamed setting. Annu Rev Immunol 31: 563-604, 2013.

12. Steinman RM: Decisions about dendritic cells: Past, present, and future. Annu Rev Immunol 30: 1-22, 2012.

13. Chen R, Deng X, Wu H, Peng P, Wen B, Li F and Li F: Combined immunotherapy with dendritic cells and cytokine-induced killer cells for malignant tumors: A systematic review and meta-analysis. Int Immunopharmacol 22: 451-464, 2014.

14. Guilliams M, Ginhoux F, Jakubzick C, Naik SH, Onai N, Schraml BU, Segura E, Tussiwand R and Yona S: Dendritic cells, monocytes and macrophages: A unified nomenclature based on ontogeny. Nat Rev Immunol 14: 571-578, 2014.

15. Anguille S, Smits EL, Lion E, van Tendeloo VF and Berneman ZN: Clinical use of dendritic cells for cancer therapy. Lancet Oncol 15: e257-e267, 2014.

16. Pizova K, Tomankova K, Daskova A, Binder S, Bajgar R and Kolarova $\mathrm{H}$ : Photodynamic therapy for enhancing antitumour immunity. Biomed Pap Med Fac Univ Palacky Olomouc Czech Repub 156: 93-102, 2012.

17. Jalili A, Makowski M, Switaj T, Nowis D, Wilczynski GM, Wilczek E, Chorazy-Massalska M, Radzikowska A, Maslinski W, Biały L, et al: Effective photoimmunotherapy of murine colon carcinoma induced by the combination of photodynamic therapy and dendritic cells. Clin Cancer Res 10: 4498-4508, 2004.

18. Saczko J, Nowak M, Skolucka N, Kulbacka J and Kotulska M: The effects of the electro-photodynamic in vitro treatment on human lung adenocarcinoma cells. Bioelectrochemistry 79: 90-94, 2010.

19. Zhang M, Tang H, Guo Z, An H, Zhu X, Song W, Guo J, Huang $X$, Chen $T$, Wang $J$ and Cao X: Splenic stroma drives mature dendritic cells to differentiate into regulatory dendritic cells. Nat Immunol 5: 1124-1133, 2004.

20. Tang H, Guo Z, Zhang M, Wang J, Chen G and Cao X: Endothelial stroma programs hematopoietic stem cells to differentiate into regulatory dendritic cells through IL-10. Blood 108: 1189-1197, 2006.

21. Xia S, Guo Z, Xu X, Yi H, Wang Q and Cao X: Hepatic microenvironment programs hematopoietic progenitor differentiation into regulatory dendritic cells, maintaining liver tolerance. Blood 112 $3175-3185,2008$
22. Li Q, Guo Z, Xu X, Xia S and Cao X: Pulmonary stromal cells induce the generation of regulatory DC attenuating T-cell-mediated lung inflammation. Eur J Immunol 38: 2751-2761, 2008.

23. Lutz MB, Kukutsch N, Ogilvie AL, Rössner S, Koch F, Romani N and Schuler G: An advanced culture method for generating large quantities of highly pure dendritic cells from mouse bone marrow. J Immunol Methods 223: 77-92, 1999.

24. Morrison TB, Weis JJ and Wittwer CT: Quantification of low-copy transcripts by continuous SYBR Green I monitoring during amplification. Biotechniques 24: 954-958, 960, 962, 1998.

25. Chidlow G, Wood JP and Casson RJ: Expression of inducible heat shock proteins Hsp27 and Hsp70 in the visual pathway of rats subjected to various models of retinal ganglion cell injury. PloS One 9: e114838, 2014.

26. Dorak MT: Real-time PCR. Taylor \& Francis 2007.

27. Fraga D, Meulia T and Fenster S: Real-time PCR. Current protocols essential laboratory techniques: 10.13. 11-10.13. 40, 2008.

28. Floto RA, MacAry PA, Boname JM, Mien TS, Kampmann B, Hair JR, Huey OS, Houben EN, Pieters J, Day C, et al: Dendritic cell stimulation by mycobacterial Hsp70 is mediated through CCR5. Science 314: 454-458, 2006.

29. MacAry PA, Javid B, Floto RA, Smith KG, Oehlmann W, Singh M and Lehner PJ: HSP70 peptide binding mutants separate antigen delivery from dendritic cell stimulation. Immunity 20 95-106, 2004

30. Wu Y, Wan T, Zhou X, Wang B, Yang F, Li N, Chen G, Dai S, Liu S, Zhang M and Cao X: Hsp70-like protein 1 fusion protein enhances induction of carcinoembryonic antigen-specific CD8+ CTL response by dendritic cell vaccine. Cancer Res 65: 4947-4954, 2005.

31. Liu Q, Zhang C, Sun A, Zheng Y, Wang L and Cao X: Tumor-educated CD11bhighIalow regulatory dendritic cells suppress $\mathrm{T}$ cell response through arginase I. J Immunol 182: 6207-6216, 2009.

32. Kansara M, Teng MW, Smyth MJ and Thomas DM: Translational biology of osteosarcoma. Nat Rev Cancer 14: 722-735, 2014.

33. Chen X, Bahrami A, Pappo A, Easton J, Dalton J, Hedlund E, Ellison D, Shurtleff S, Wu G, Wei L, et al: Recurrent somatic structural variations contribute to tumorigenesis in pediatric osteosarcoma. Cell Rep 7: 104-112, 2014.

This work is licensed under a Creative Commons Attribution-NonCommercial-NoDerivatives 4.0 International (CC BY-NC-ND 4.0) License. 